\title{
Prospects of Big Data Analytics in Africa Healthcare System
}

\author{
Akindele Akinnagbe ${ }^{1}$, K.Dharini Ami Peiris ${ }^{1} \&$ Oluyemi Akinloye ${ }^{2}$ \\ ${ }^{1}$ Department of Information Systems and Operations Management, University of Auckland, Auckland, New \\ Zealand \\ ${ }^{2}$ Department of Medical Laboratory Science, College of Medicine of the University of Lagos, Idi-Araba, Lagos, \\ Nigeria \\ Correspondence: Professor Oluyemi Akinloye, Department of Medical Laboratory Science, College of Medicine \\ of the University of Lagos, Idi-Araba, Lagos, Nigeria. E-mail: oakinloye@unilag.edu.ng
}

Received: February 17, 2018 Accepted: April 3, 2018 Online Published: May 9, 2018

doi:10.5539/gjhs.v10n6p114 URL: https://doi.org/10.5539/gjhs.v10n6p114

\begin{abstract}
Big data is having a positive impact in almost every sphere of life, such as in military intelligence, space science, aviation, banking, and health. Big data is a growing force in healthcare. Even though healthcare systems in the developed world are recording some breakthroughs due to the application of big data, it is important to research the impact of big data in developing regions of the world, such as Africa. Healthcare systems in Africa are, in relative terms, behind the rest of the world. Platforms and technologies used to amass big data such as the Internet and mobile phones are already in use in Africa, thereby making big data applications to be emerging. Hence, the key research question we address is whether big data applications can improve healthcare in Africa especially during epidemics and through the public health system. In this study, a literature review is carried out, firstly to present cases of big data applications in healthcare in Africa, and secondly, to explore potential ethical challenges of such applications. This review will provide an update on the application of big data in the health sector in Africa that can be useful for future researchers and health care practitioners in Africa.
\end{abstract}

Keywords: Africa, data analytics, big data, epidemics, healthcare system

\section{Introduction}

According to Wamba et al. (2015), big data is an all-inclusive approach to managing, processing and analysing huge volumes of data for providing insights, so that we can have a better advantage when making decisions. Revolution of big data has brought tremendous advancement in law enforcement and military intelligence, space science, aviation, banking and in almost every aspect of human endeavour due to application of big data. The healthcare sector is not left behind in terms of improvement in service delivery due to application of big data. Historically, the healthcare sector is such that it generates huge volumes of data, which is propelled by keeping meticulous patient-health records (Raghupathi, 2010). In the past, records were stored as hard copies. Now, records are digitized, leading to large volumes of data being generated. In the era of big data, the velocity of generating data is very high such that the U.S. healthcare industry alone attained 150 exabytes as in 2011, which could soon reach yottabytes (Dembosky, 2012). There is no doubt that era of digitized records, has helped improve quality of healthcare delivery, reduce healthcare costs, improve efficiency in disease surveillance, and enhance public health management. From the literature search carried out in this study, much of the big data applications in the health sector, have been in developed regions of the world. For instances, google scholar search for big data in healthcare in Africa returns 85,000 results in comparison 155,000 of the United States. It is logical to assume that big data has a big role to play in improving the health sector of under-developed regions of the world.

One such under-developed regions of the world is Africa, and technically, the continent is adjudged to be an unhealthy continent due to prevalence of epidemics and inadequate infrastructure to sustain healthcare (KPMG, 2012). While there is apparent inadequate infrastructure to sustain good healthcare in many parts of Africa, there is evolution of use of mobile technologies such as mobile phones. For instance, users of mobile phones subscription in Africa as at February (2016) have reached about 700 million (Adepetun, 2016). Such huge mobile phones subscription also means huge generation of big data. Despite slow growth in the application of big data in Africa, recent evidence indicates the usefulness of mobile phone data and social media such as Facebook in tracking and eradicating epidemics, though with some challenges. Due to lack of awareness of big data usefulness within Africa, 
it is important to report its roles and potentials. Thus, the purpose of this study is to report the prospects of big data in African healthcare. It is hoped that this review will provide an update on the application of big data in the health sector in Africa continent, and spur others to research this invaluable problem.

\section{HealthCare Informatics}

At the root of quality healthcare delivery is healthcare informatics. Records have proved that health informatics which encompasses how information technology is used to enhance healthcare (O'Carroll et al., 2003), has led to improvement in the healthcare system. Efficient healthcare delivery is information-driven, just like other business enterprises. Physicians and other Healthcare personnel need adequate and the right kind of data in order to diagnose diseases, prescribe drugs and provide appropriate counsel to patients. In like manner, healthcare managers rely on quality information in order to make right decisions. For instance, provision of appropriate personnel in hospitals, management of facilities and drugs inventories, and efficient management of disease outbreak of public interest is based on information management.

In many countries with efficient healthcare systems, the backbone of healthcare delivery is a healthcare information system based on robust health informatics. Health informatics ensures management of data that health personnel and institutions need to perform their duties resourcefully. Such healthcare information systems enable communication, synchronisation of information, and coordination of action among many professionals within healthcare (Mach \& Salem, 2010).

Due to the availability of tools in the current digital age, huge potentially informative electronic data in healthcare are now being amassed from numerous sources. For example, a California-based health outfit named Kaiser Permanente, with more than 9 million clients, is reported to have between 26.5 and 44 petabytes client records that, includes notes and images (Transformation, 2013).

In countries with less efficient healthcare, it is on record that advent of information technology has served as a tool used to improve healthcare delivery. For example, World Health Organisation (WHO) once provided Mongolia with personal computers in order to improve health care delivery in the country (Idowu et al., 2008). Africa, which is the focus of this review, has experienced steady improvement in healthcare as a result of the advent of the Internet, use of mobile phones, and social media. A study from Cameroon indicates that the implementation of an electronic health record system is improving primary healthcare (Kamadejeu et al., 2005).

\section{Big Data Analytics in Healthcare}

Although businesses are the biggest player in the use and application of big data, healthcare sector has been active in the application of big data in recent times. In many cases, big data applications have assisted in reducing the cost of healthcare (Kamadejeu et al., 2005), helped in the diagnosis and in the prescription of suitable treatment pathways to patients, ensured healthcare systems monitoring and augmented accountability. Traditionally, doctors use their experience and judgment to diagnose and to make clinical decisions. However, in this era of big data, decisions made by health professionals are edging towards evidence-based medicine (Costa, 2009). Hence, patient information and data generated by other health professionals especially laboratories and radiology are transmitted to the physician in a timely manner. This further increases data that are available to make better-informed decisions for patient's care.

In healthcare, the rate of generation of electronic health records in the present dispensation is high and such data are diverse in datatype and complexity to the extent that they cannot be processed with traditional software/hardware or with conventional data management tools and methods. The totality of this diverse data that is generated make up the "big data" in healthcare. Such data include, clinical data, doctor's comments and prescriptions, medical imaging, laboratory test results, pharmaceutical records, health insurance reports, administrative reports, patient historical data, posts on social media platforms such as, Facebook and Twitter, blogs, and other information that are not directly connected to patients, such as, news in health magazines and relevant publications in medical journals (Raghupathi \& Raghupathi, 2013).

Just like in the business world, availability of big data in the healthcare sector, presents an opportunity to discover relationships, patterns and trends within the data. Information derived from such sources has the capability of improving healthcare and lowering cost of healthcare. Therefore, what big data analytics can do in healthcare is, to utilise the benefits of large volumes of diverse data to obtain insights so that healthcare professionals and administrators alike, can make life-changing decisions (Raghupathi \& Raghupathi, 2014). When there is synthesis and analysis of big data in healthcare, there is revelation of associations, patterns and trends leading to insights that providers and stakeholders in healthcare can utilise in lowering the cost of healthcare, making better diagnosis and finding and using better treatments of diseases, monitoring epidemics and preventing new epidemics. We believe 
that this will enable overall improvement in healthcare can be achieved in regions such as Africa.

Due to the potential benefits of big data in healthcare, analytics of big data in healthcare is now an emerging discipline in medical science. In recognizing the benefits of big data in healthcare, the United States government in (2012) invested about \$200 million into a "Big Data and Development Initiative in Medical Research" with the goal of transforming the use of big data for scientific innovation and medical care (White House, 2012). As a result, numerous healthcare-related organisations began to apply for funding in big data healthcare.

Application of big data in healthcare has improved the healthcare system in developed regions of the world, giving an indication that healthcare systems in the developing regions of the world can also be improved by the use of big data. Further in this review, potentials of big data application in healthcare in the African continent will be discussed. However, it is important to note that though big data in itself is a good source, it contributes nothing to healthcare if it is not used intelligently and deployed in such a way as to provide insight for better decision-making. For this reason, application of business intelligence and data analytics becomes very important in the application of big data in healthcare. The next section of this report will discuss the role of business intelligence in healthcare.

\section{Use of Business Intelligence and Data Analytics in Healthcare}

From past literature, numerous definitions of Business Intelligence (BI) were found (Baars \& Kemper, 2008; Lamont, 2006; Brannon, 2010; Bhatnagar, 2009). In summary, BI is a tool, a technology, a process, a methodology and an architecture used to collect data and store and analyse data, in order to provide deeper insights that will help in better decision making. BI is proven to have the capability to operationalise repository data such as medical records so that evidence-based medical practice is possible, thereby improving healthcare delivery. Due to the dynamics of our society in terms of changes in laws, regulations, and the amount of data generated, healthcare organisations are employing business intelligence (BI) solutions to utilise data for accurate decision-making in order to help improve services provided to patients, reduce administrative and service costs, and safeguard the prospect of healthcare industry (Ashrafi, Kelleher, \& Ku, 2014). Healthcare providers and professionals now treat healthcare delivery as a business, thereby propelling BI to gain tremendous attention in this sector (Bonney, 2016). $\mathrm{BI}$ as an architecture provides a framework that shows processes, which connect both internal and external actors within the healthcare environment (Mettler \& Vimarlund, 2009). Thus, decision makers in healthcare need to be mindful of those processes in order to have an understanding of the usefulness of BI in healthcare.

In general, the healthcare environment at present is not in shortage of data. The challenge is how to transform the huge amount of data into useful information and actionable knowledge, and that is why $\mathrm{BI}$ is relevant in healthcare (Yi, et al., 2008). An example of BI application in healthcare is the use of BI dashboard software to help healthcare providers to adapt quickly to the Obama healthcare act (Bitner, 2014). The Obama healthcare act places emphasis on the quality of healthcare delivery, rather than the number of patients treated. When the act became law, healthcare providers across America were concerned as they struggled to stay in business. However, using BI software, healthcare providers were able to forecast the financial and operating costs of the Obama healthcare act and know how to maintain or even enhance their efficiency.

The worldwide healthcare BI market is presently valued at an estimated $\$ 3,596$ million and is expected to increase to $\$ 4,739$ million in 2018 (Markets \& Markets, 2014). Key factors responsible for this growth are the emerging big data in healthcare, improvement in healthcare delivery, and satisfaction of patients. United States leads the healthcare business intelligence market followed by Asian countries that are fast adopting BI in healthcare such as China, India, Singapore and Malaysia. Adoption of BI in healthcare in African Countries are emerging and it is expected to grow due to the rise in usage of mobile technologies, social media platforms by the populace, rise in the adoption of cloud computing and rise in the use of electronic medical data within the healthcare community.

\section{HealthCare in Africa}

The African continent has the highest mortality rate the world, and as at today, it is the only region of the world where deaths from communicable diseases exceeds the deaths from chronic diseases (Deaton \& Tortora, 2016). For instance, the continent population is disabled with epidemic of diseases such as Malaria, HIV/AIDS, Polio, and in recent times the Ebola virus (Aikins \& Marks, 2007). In (2005), about $18.8 \%$ of the 58.03 million global deaths are from Africa, and about $64 \%$ of these deaths were as a result of diseases (Kirigia \& Barry, 2008). As noted by some researchers, these diseases are preventable, but there exists a weak healthcare system, dwarfed by limited and inaccurate information on disease prevalence, spread and surveillance (Unwin, et al., 2001; Coope et al., 1998). Some of the endemic epidemic disease in Africa such as HIV, Polio and Ebola can be prevented through early detection and efficient surveillance. However, in many African countries, necessary surveillance is not available due to wars, scarcity of competent health professionals, and a shortage of infrastructure to gather and 
monitor data (Anema et al., 2014).

Reasons for the poor state of healthcare in Africa can be attributed to long-term wars in many parts of Africa, corruption and poor accountability of public office holders, and low spending on health care (Deaton \& Tortora, 2016). For this reason, significant proportion of aids from western countries goes to Africa, and much of those aids have been directed to healthcare (OECD, 2011). The gain of this has been an improvement in life expectancy after 1950, but it is sad that this gain has been eroded by the year 2000 due to several epidemics including HIV (Deaton, 2013), malaria, polio and in recent time, Ebola virus.

In many places, health agencies traditionally rely on data obtained from government health ministries, which are not from sources with surveillance depth. The poor state of healthcare in Africa does not mean that healthcare in Africa will be in a pathetic state forever, but rather, that the state of healthcare in Africa indicates the continent has great prospects for big data applications in healthcare. Though application of big data and BI in healthcare is still at the rudimentary level in Africa due to some bottlenecks, rise in the use of internet and mobile technologies in Africa have provided a platform for the generation of data, which are potentially useful in healthcare. In addition, few reports within the continent have revealed that the application of big data in healthcare looks promising. Further sections of this review will focus on cases studies of such big data application in Africa.

\section{Big Data Application Through the Use of Digital Surveillance in the HealthCare System in Africa}

Although application of big data in Africa is still in its infancy, recent reports have shown that success has been achieved through the use of digital surveillance to track epidemics (Nsoesie et al., 2015; Chang et al., 2009; Liu et al., (2016)). Even though there are ethical issues to contend with in the use of big data in Africa, an outbreak of an epidemic, sometimes many epidemics become a national crisis as well as a global crisis. As actions have to be taken to save lives, governments have to make political decisions to save such situations at all cost. It is for this reason that big data application has been deployed in healthcare in recent times to stem outbreaks of epidemics. One big step that healthcare administrators in Africa have taken in recent times that have paved way for the use of big data is the use of electronic surveillance to detect outbreaks of infectious disease. In combatting infectious diseases, early detection and surveillance is critical. A digital surveillance that has been used successfully used globally and in Africa is HealthMap.

\subsection{HealthMap}

HealthMap is an open source automated electronic information system for presenting data on disease outbreaks based on geography, time, and infectious disease carriers (Brownstein \& Freifeld, 2007). Health organisations such as WHO rely on systems such as a HealthMap to detect epidemics. For instance, the dreaded Ebola outbreak in West Africa first came to global knowledge on 14th March, (2014), after HealthMap retrieved it from a French news website that reported a deadly fever in Guinea. Based on that report, Sierra Leone which shares border with Guinea officially declared on 23rd of March, that Ebola might have spread into Sierra Leone. Then on the 8th of August (2014), WHO declared Ebola as an outbreak of public health emergency of international concern. In addition, through HealthMap surveillance, new cases of Polio was detected in a war-torn north-western Nigeria. The strength of HealthMap as a disease location detection tool is based in its capability to pool huge, diversed and unstructured Internet data, and extract useful information for users of public health (Freifeld et al., 2008). The system collects alerts on a daily basis, categorises them based on the disease and the location, saves them in a database, and then visualises them to the user.

\section{Case Studies of Big Data Application in Healthcare Systems in Africa}

\subsection{Dealing with Ebola Epidemics Using Big Data}

The recent outbreak of Ebola virus disease (EVD) in Western Africa which was first reported in March (2014), ravaged that region of the world such that within six months, there were more than 4500 reported cases as well as close to 2300 deaths in five West African countries (WHO, 2014). Within two years, reported cases have increased to about 28,657, and about 11,325 deaths (CDC, 2016; WHO, 2016). Due to the fact that the Ebola virus spreads primarily through contact with someone who has the virus, spreading the disease can be stemmed effectively through a combination of efficient surveillance, early detection, tracing of patients' movement, isolation of patient and care and safe burial of deaths due to the disease. When the EVD was discovered in March (2014) through the initiative of HealthMap, lack of adequate disease surveillance systems in the affected regions seriously hampered the ability of governments and stakeholders to respond locally. It also increased the spread of the disease to other countries. While emergency medical organisations, such as WHO, some charity organisations, and various governmental bodies, labour to control the EVD epidemics, a growing number of data scientists began to brainstorm on how big data analytics can be of used to stamp out the disease. 
One tool that was useful during the Ebola crisis were mobile phones. Mobile phones are widely owned in many African countries, including the regions ravaged by Ebola (Jeffrey \& Versteeg, 2007). During the Ebola crises, data scientists tapped into the rich source of data provided by phone companies, to visualise population movements of Ebola Patients and forecast of how the EVD can spread. For instance, a telecom provider in one of the countries affected in West Africa, supplied anonymised voice calls and text messages from about 150,000 mobile phones to Flowminder, a Swedish non-govenmental organisation (Wall, 2014). This data was eventually used to produce detailed maps (Figure 1) showing movements of Ebola patients. Based on this, authorities planned on best places to set up treatment centres, and in a controversial manner, devise means to limit travel in order to control the disease.

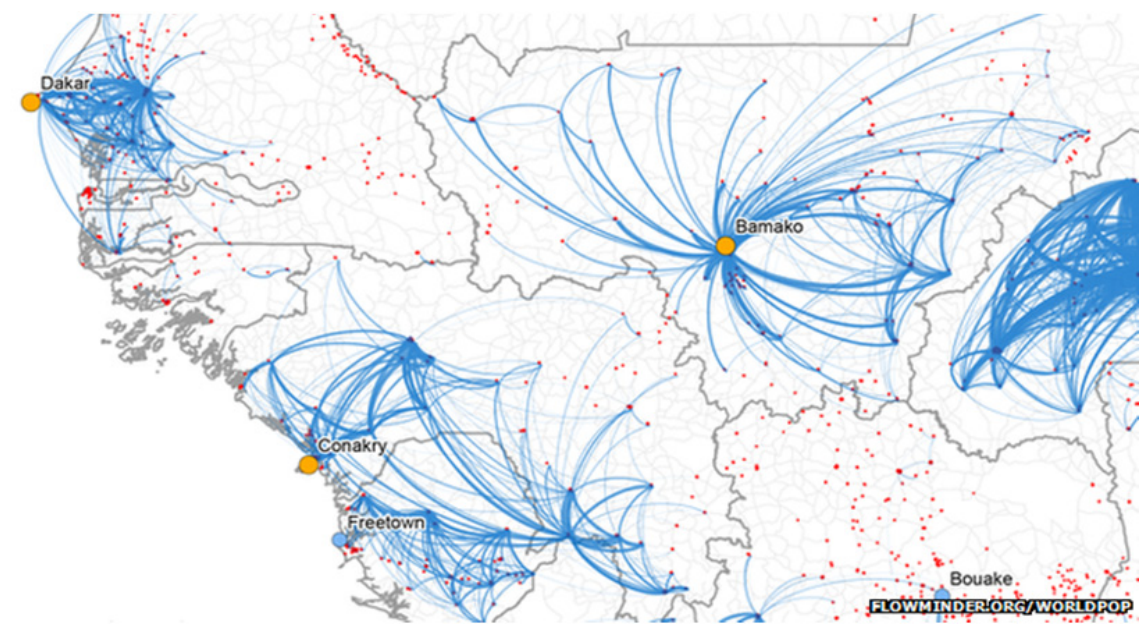

Figure 1. Movements of Ebola patients in (2014) based on Mobile phone data from West Africa (Adapted from Wall, 2014)

\subsection{Fighting HIV Epidemics Using Big Data}

Human Immunodeficiency Virus (HIV) is a virus that causes HIV disease and will over time lead to Acquired Immunodeficiency Syndrome (AIDS). AIDS is a progressive weakness in the immune system of patients with HIV disease such that allows life-threatening opportunistic diseases and cancers to flourish (Douek, Roederer and Koup, 2009). According to a United Nations report, on HIV/AIDS has identified public health practices in Africa as being one of the major causes of death on the continent. According to a UN report, about $70 \%$ of people living with HIV in the world live in sub-Saharan Africa (UNAIDS, 2012). The virus can be transferred between sexual partners and from an HIV-infected mother to her foetus during pregnancy, newly born at childbirth, and during breastfeeding. Early diagnosis of the disease can prevent the spread and afford infected patients to be treated as quickly as possible.

Though diagnosis of HIV is readily available in different parts of Africa, logistics involved in the testing can be complex, and prolonged waiting time to get results can cause psychological trauma for many people. Through the use of big data, Jérémie Gallien of the London Business School and his co-researchers were able to explore big data to reduce the logistics time for HIV testing, and thus improve the chance of early diagnosis of the disease (Deo et al., (2015)). Jérémie and colleagues did that by analysing logistics data of about 30,000 records containing information shipment records of samples from clinic to the laboratory and the eventual outcomes on patients.

\subsection{Using Big Data to Develop Effective Malaria Control Programme}

Like HIV, about $90 \%$ of malaria deaths in the world today occur in the sub-Saharan Africa (WHO, 2016). This is due to the fact that Anopheles gambiae, which is most effective malaria vector carrying most dangerous human malaria parasites (Plasmodium falciparum) is in Africa. Malaria kills about one million people annually in Africa, and majority of these are children under the age of five (Role Back Malaria, 2010). Due to the fact that malaria parasite can be transmitted from person to person, an efficient control of the infection may be to monitor movement of people. In order to assist Kenyan government to develop an effective malaria control programme, Wesolowski et al., (2012) monitored malaria parasite movement by analyzing data of mobile phones of about 15 million people in within one year. The result of this analysis when compared with hospital records in Kenya reveal malaria transmission in places generally believed not to have the infection. 


\section{Mobile Phones and Social network as Rich Sources of Big Data}

Although application of big data and business intelligence is still in its infancy in Africa in comparison with its application in developed regions of the world, evidence presented in this review provides insight that big data analytics is emerging in Africa and can be a big weapon to improve healthcare and to end many diseases plaguing the continent. Even though sophisticated equipment may not be in place in many parts of Africa to provide world class healthcare, increased use of social networks (Facebook, Twitter, WhatsApp, WeChat etc.), mobile devices and the internet in Africa is making possible the generation of data that can be used for disease surveillance. It is for this reason that few research efforts on the usefulness of big data in African healthcare made use of data from mobile phones, and social media.

Africa as a continent has taken the lead in the worldwide shift from fixed phones to mobile phones (UN, 2010), making it easier to collect data on people's behaviour as it relates with disease surveillance. There is an emerging field in the field of public health called digital epidemiology, which deals with how big data can be used to detect, understand, and tackle public health challenges (Salathe et al., 2012). With the increase in the use of social media and mobile phones in Africa, there is a crucial need to increase the effort on how to use big data emanating from social media network and mobile phones to monitor, prevent, detect, and treat diseases, just as it is being done in the developed regions of the world. For instance, when about 553 million tweets in the United States were collected online and sifted using HIV related keywords, the result of the analyses shows that there was a strong positive correlation between HIV-related tweets and reported HIV cases across the United States (Young et al., 2014). This suggests the usefulness of data from social network as a tool to evaluate and prevent diseases. Despite the huge health burden of contagious diseases in Africa, big data from social media and mobile phones provide a unique opportunity to monitor risk of disease transmission.

\section{Conclusion}

Despite the prevailing challenges and limitations in Africa, there is evidence that big data analytics has the capacity to transform the healthcare system in Africa. Preliminary application in the public health system especially when epidemics happen is proven evidence of its potential benefits in the African healthcare system. Unfortunately, not much use and benefit have been reported in non-communicable and chronic diseases in Africa unlike her developed countries counterpart, especially United States. However, with an increase in the use of mobile technologies and social media in Africa, coupled with emerging investments into big data technology, it is likely that we will witness a rapid, extensive implementation and use of big data analytics in healthcare across the Africa continent as big data analytics becomes an emerging and cost-effective tool in improving global healthcare. In Africa, issues such as big data analytics as affected by enabling laws and governance, cultural and privacy issues, data security, and ethical standards will be gaining attention. Additionally, in order to make the gains of big data to be sustainable, there is need for stakeholders in the Africa health industry to put in place a business intelligence roadmap so that data from diverse data sources can be enabled, mined, and transformed into useful actionable knowledge for the benefit of the community. Big data analytics applications in healthcare are still at its infancy in Africa. Thus, reporting success stories of its application can help fast track its adoption on the continent.

\section{Competing Interests Statement}

The authors declare that they have no competing or potential conflicts of interest.

\section{References}

Adepetun, A. (2016). Africa: Mobile Phone Users in Nigeria, South Africa, Kenya Hit 700 Million. Retrieved from $\mathrm{http} / / /$ allafrica.com/stories/201602170661.html

Aikins, A. D., \& David F. M. (2007). Health, Disease and Healthcare in Africa. Journal of Health Psychology (SAGE Publications) 12(3), 387-402. https://doi.org/10.1177/1359105307076228

Anema, A., Sheryl, K., Kumanan, W., Robert, S. H., Kamran, K., ..., John, S. B. (2014). Digital surveillance for enhanced detection and response to outbreak. The Lancet, Infectious diseases 14(11), 1035. https://doi.org/10.1016/S1473-3099(14)70953-3

Ashrafi, N., Lori, K., \& Jean-Pierre, K. (2014). The impact of business intelligence on healthcare delivery in the USA. Interdisciplinary Journal of Information, Knowledge, and Management, 9, 117-130. https://doi.org/10.28945/1993

Baars, H., \& Hans-George, K. (2008). Management Support with Structured and Unstructured Data-An Integrated Business Intelligence Framework. Information Systems Management, 132-148. https://doi.org/10.1080/10580530801941058 
Bhatnagar, A. (2009). Web Analytics for Business Intelligence: Beyond Hits and Sessions. Online, 33(6), 32-35.

Bitner, Saar . (2014). How Healthcare Tackles Big Changes Using Bi. June 16. Retrieved September 7th, 2016, from https://www.sisense.com/blog/healthcare-can-tackle-big-changes-using-bi/.

Bonney, W. (2016). Applicability of Business Intelligence in Electronic Health Record. Social and Behavioral Sciences, 73, 257-262. https://doi.org/10.1016/j.sbspro.2013.02.050

Brannon, N. (2010). Business intelligence and E-discovery. Intellectual Property \& Technology Law Journal, 22(7), 1-5.

Brownstein, J. S., \& Freifeld, C. C. (2007). HealthMap: The development of automated real-time internet $\begin{array}{lllll}\text { surveillance for epidemic intelligence. } & \text { Eurosurveillance, } & 12(48), & 3322 .\end{array}$ https://doi.org/10.2807/esw.12.48.03322-en

CDC. (2016). (2014). Ebola Outbreak in West Africa. June 22. Reteived September 16, 2016, from. http://www.cdc.gov/vhf/ebola/outbreaks/2014-west-africa/

Chang, A. Y., Parrales, M. E., Jimenez, J., \& Sobieszczyk, M. E. (2009). Combining Google Earth and GIS mapping technologies in a dengue surveillance system for developing countries. International journal of health geographics, 8(1), 49. https://doi.org/10.1186/1476-072x-8-49

Coope, R. S., Babatunde, O., Jay, S. K., \& Terrence, F. (1998). Disease burden in sub-Saharan Africa: what should we conclude in the absence of data? Lancet, 351(9097), 208-210. https://doi.org/10.1016/S0140-6736(97)06512-4

Costa, F F. (2009). Enomics, epigenomics and personalized medicine: A bright future for drug development? Bioforum Eur, (13), 29-31.

Deaton, Angus S, and Robert Tortora. (2016). "People In Sub-Saharan Africa Rate Their Health And Health Care Among The Lowest In The World." Health Affairs 34 (3): 519-527. https://doi.org/10.1377/hlthaff.2014.0798

Deaton, Angus. (2013). The great escape: health, wealth, and the origins of inequality. Princeton: Princeton University Press. https://doi.org/10.5860/CHOICE.51-3351

Dembosky, A. (2012). Big Data: Data prescription for better healthcare. Financial Times, 12, 11.

Deo, S., Gallien, J., \& Jónasson, J. O. (2015). Improving HIV early infant diagnosis supply chains in sub-Saharan Africa: Models and application to Mozambique. Social Science Research Network. https://doi.org/10.2139/ssrn.2511549

Douek, D. C., Roederer, M., \& Koup, R. A. (2009). Emerging concepts in the immunopathogenesis of AIDS. Annual review of medicine, 60, 471-484. https://doi.org/10.1146/annurev.med.60.041807.123549

Freifeld, C. C., Mandl, K. D., Reis, B. Y., \& Brownstein, J. S. (2008). HealthMap: global infectious disease monitoring through automated classification and visualization of Internet media reports. Journal of the American Medical Informatics Association, 15(2), 150-157. https://doi.org/10.1197/jamia.M2544

Jeffrey, J., \& Versteeg, M. (2007). Mobile phones in Africa: how much do we really know. Social Indicators Research, 84(1), 117. https://doi.org/10.1007/s11205-006-9079-x

Idowu, P., Cornford, D., \& Bastin, L. (2008). Health informatics deployment in Nigeria. Journal of Health Informatics in Developing Countries, 2(1).

Jee, K., \& Kim, G. H. (2013). Potentiality of big data in the medical sector: focus on how to reshape the healthcare system. Healthcare informatics research, 19(2), 79-85. https://doi.org/10.4258/hir.2013.19.2.79

Kamadjeu, R., Tapang, E., \& Moluh, R. (2005). Designing and implementing an electronic health record system in primary care practice in sub-Saharan Africa: a case study from Cameroon. Journal of Innovation in Health Informatics, 13(3), 179-186. https://doi.org/10.14236/jhi.v13i3.595

Kirigia, J., \& Barry, S. (2008). Health challenges in Africa and the way forward. https://doi.org/10.1186/1755-7682-1-27

Knowledgent. (2016). Big Data and Healthcare Payers. Knowledgent. Retrieved September 7th, 2016, from https://knowledgent.com/whitepaper/big-data-and-healthcare-payers/

KPMG. (2012). The state of healthcare in Africa. KPMG. Retrieved August 8, 2016, from https://www.kpmg.com/Africa/en/IssuesAndInsights/Articles-Publications/Documents/The-State-of-Health care-in-Africa.pdf. 
Lamont, J. (2006). Business Intelligence: The text analysis strategy. KM World, 15(10), 8. Retrieved September 7th, 2016 from http://www.kmworld.com/Articles/Editorial/Features/Business-Intelligence-The-text-analysis-strategy-1852 6.aspx.

Liu, K., Li, L., Jiang, T., Chen, B., Ji, Z., Wang, Z., .., Gu, H. (2016). Chinese Public Attention to the Outbreak of Ebola in West Africa: Evidence from the Online Big Data Platform. International journal of environmental research and public health, 13(8), 780. https://doi.org/10.3390/ijerph13080780

Mach, M. A., \& Abdel-Badeeh, M. S. (2010, November). Intelligent techniques for business intelligence in healthcare. In Intelligent Systems Design and Applications (ISDA), 2010 10th International Conference on (pp. 545-550). IEEE. https://doi.org/10.1109/ISDA.2010.5687209

Markets and Markets. (2014). Healthcare Business Intelligence (BI) Market by Function (Reporting, OLAP, Monitoring), Application (Clinical \& Financial), Technology (Traditional, Cloud, Mobile), End User (Hospitals, Clinics, ACO, HIE, Payers) - Trends \& Global Forecasts to 2018. May. Retrieved September 7th, 2016, from http://www.marketsandmarkets.com/Market-Reports/healthcare-business-intelligence-market252368925.html

Mettler, T., \& Vimarlund, V. (2009). Understanding business intelligence in the context of healthcare. Health informatics journal, 15(3), 254-264. https://doi.org/10.1177/1460458209337446

Nsoesie, E. O., Kluberg, S. A., Mekaru, S. R., Majumder, M. S., Khan, K., Hay, S. I., \& Brownstein, J. S. (2015). New digital technologies for the surveillance of infectious diseases at mass gathering events. Clinical Microbiology and Infection, 21(2), 134-140. https://doi.org/10.1016/j.cmi.(2014).12.017

O'Carroll, P. W., William, A. Y., Elizabeth, M. W., Laura, H. R., \& Ernest L. M. (2003). Public Health Informatics and Information Systems. New York: Springer. https://doi.org/10.1007/b98877

OECD. (2011). Measuring Aid: 50 years of DAC statistics - 1961-2011. OECD. April. Retrieved September 7th, 2016, from https://www.oecd.org/dac/stats/documentupload/MeasuringAid50yearsDACStats.pdf.

Raghupathi, W. (2010). Data Mining in Health Care. In S. Kudyba (Ed.), Healthcare Informatics: Improving Efficiency and Productivity (pp. 211-223). Taylor \& Francis.

Raghupathi, W., \& Raghupathi, V. (2013). An overview of health analytics. J Health Med Informat, 4(3), 1-11. https://doi.org/10.4172/2157-7420.1000132

Raghupathi, W., \& Raghupathi, V. (2014). Big data analytics in healthcare: promise and potential. Health information science and systems, 2(1), 3. https://doi.org/10.1186/2047-2501-2-3

Role Bac Malaria. (2010). The burden of malaria in Africa. Role Back Malaria. https://www.againstmalaria.com/downloads/RBMBurdenMalariaAfrica.pdf.

Salathe, M., Bengtsson, L., Bodnar, T. J., Brewer, D. D., Brownstein, J. S., Buckee, C., ... \& Vespignani, A. (2012). $\begin{array}{lllll}\text { Digital epidemiology. PLoS computational biology, } & \text { (7), } 1002616 .\end{array}$ https://doi.org/10.1371/journal.pcbi.1002616

Transformation, Institute for Health Technology. (2013). Transforming Health Care through Big Data Strategies for leveraging big data in the health care industry. Institute for Health Technology Transformation. Institute for Health Technology Transformation. January 10th. Retrieved September 7th, 2016, from http://ihealthtran.com/big-data-in-healthcare.

UN. (2010). A social media boom begins in Africa. https://doi.org/10.18356/ff4217a4-en

UNAIDS. (2012). Global Fact Sheet: World Aids Day (2012). UNAIDS. Retrieved September 16, 2016, from http://files.unaids.org/en/media/unaids/contentassets/documents/epidemiology/2012/gr2012/20121120_Fact Sheet_Global_en.pdf.

Unwin, N., Setel, P., Rashid, S., Mugusi, F., Mbanya, J. C., Kitange, H., ... \& Alberti, K. G. M. M. (2001). Noncommunicable diseases in sub-Saharan Africa: where do they feature in the health research agenda? Bulletin of the World Health organization, 79(10), 947-953.

Wall, M. (2014). Ebola: Can big data analytics help contain its spread. BBC News.Retrieved from http://www.bbc.com/news/business-29617831

Wamba, S. F., Akter, S., Edwards, A., Chopin, G., \& Gnanzou, D. (2015). How 'big data'can make big impact: Findings from a systematic review and a longitudinal case study. International Journal of Production 
Economics, 165, 234-246. https://doi.org/10.1016/j.ijpe.2014.12.031

Wesolowski, A., Eagle, N., Tatem, A. J., Smith, D. L., Noor, A. M., Snow, R. W., \& Buckee, C. O. (2012). Quantifying the impact of human mobility on malaria. Science, 338(6104), 267-270. https://doi.org/10.1126/science.1223467

White House, US. (2012). Executive Office of the President. Retrieved September 7th, 2016, from https://www.whitehouse.gov/sites/default/files/microsites/ostp/big_data_press_release.pdf

WHO. (2016). Ebola data and statistics. January 31. Accessed September 16, 2016. http://apps.who.int/gho/data/view.ebola-sitrep.ebola-summary-latest?lang=en

—. (2016). Malaria. April. Accessed September 19, 2016. http://www.who.int/mediacentre/factsheets/fs094/en/

WHO Ebola Response Team. (2014). Ebola virus disease in West Africa-the first 9 months of the epidemic and forward projections. New England Journal of Medicine, 371(16), 1481-1495. https://doi.org/10.1056/NEJMoa1411100

Yi, Q., Hoskins, R. E., Hillringhouse, E. A., Sorensen, S. S., Oberle, M. W., Fuller, S. S., \& Wallace, J. C. (2008). Integrating open-source technologies to build low-cost information systems for improved access to public health data. International Journal of Health Geographics, 7(1), 29. https://doi.org/10.1186/1476-072X-7-29

Young, S. D., Rivers, C., \& Lewis, B. (2014). Methods of using real-time social media technologies for detection and remote monitoring of HIV outcomes. Preventive medicine, 63, 112-115. https://doi.org/10.1016/j.ypmed.2014.01.024

\section{Copyrights}

Copyright for this article is retained by the author(s), with first publication rights granted to the journal.

This is an open-access article distributed under the terms and conditions of the Creative Commons Attribution license (http://creativecommons.org/licenses/by/4.0/). 